\title{
Pregnancy in uterus didelphys delivered by caesarean section: a case report
}

\author{
Devyani Sawai ${ }^{1 *}$, Susheel K. Sharma ${ }^{2}$, Devashish S. Sawai ${ }^{3}$, Uttkarsha Sawai ${ }^{4}$, \\ Sangeeta Sharma ${ }^{5}$, Ajay Sharma ${ }^{6}$
}

\author{
${ }^{1}$ Department of Obstetrics and Gynecology, PGIMS Rohtak, Rohtak, Haryana, India \\ ${ }^{2}$ Department of Medicine, Oscar Superspeciality and Trauma Centre, Rohtak, Haryana, India \\ ${ }^{3}$ Department of Orthodontics, Government Doon Medical College, Dehradun, Uttarakhand, India \\ ${ }^{4}$ Department of Law, Symbiosis Law College, Pune, Maharashtra, India \\ ${ }^{5}$ Department of School Education, J and K Government, Jammu, J and K, India \\ ${ }^{6}$ Department of Electronics and Communications, CGC Landran, Mohali, Chandigarh, India
}

Received: 02 September 2017

Accepted: 25 September 2017

\author{
*Correspondence: \\ Dr. Devyani Sawai, \\ E-mail: devyani7187@gmail.com
}

Copyright: (C) the author(s), publisher and licensee Medip Academy. This is an open-access article distributed under the terms of the Creative Commons Attribution Non-Commercial License, which permits unrestricted non-commercial use, distribution, and reproduction in any medium, provided the original work is properly cited.

\begin{abstract}
The aim of this study is to report a rare case of pregnancy in uterus didelphys. Mullerian duct anomalies are congenital defects of the female genital system that arise from abnormal embryological development of the Mullerian ducts. A didelphys uterus, also known as double uterus is one of the least common amongst the various Mullerian duct anomalies. It results from complete failure of fusion of Mullerian ducts. There is presence of double uterine bodies with two separate cervices and often double or septate vagina. We report the case in our institute of a pregnancy in the left sided body of a didelphys uterus, delivered by caesarean section. Patients with uterus didelphys belong to high risk group and complications are increased in malformed uterus. Such cases need a meticulous prenatal care. It is a rare Mullerian anomaly and can present with varied obstetrical and gynaecological complications. Prompt and accurate diagnosis of uterine malformations and appropriate surgical intervention are essential to prevent complications.
\end{abstract}

Keywords: 3D ultrasonography, Caesarean section, Mullerian duct anomaly, Uterus didelphys

\section{INTRODUCTION}

The human uterus is of paramesonephric origin. Fusion of two paramesonephric ducts and formation of vaginal canal are completed usually between tenth and seventeenth week of intrauterine development.

The prevalence rate of uterine malformations in general fertile population is $0.001-10 .{ }^{1}$ Septate uterus is the commonest uterine anomaly with a mean incidence of $35 \%$, followed by bi-cornuate uterus i.e. $25 \%$, arcuate uterus $20 \%$ and uterus didelphys being the least common $(8 \%)$. Uterus didelphys or double uterus is an embryological abnormality, which results from failure of lateral fusion of Mullerian ducts, resulting in two hemiuteruses and two cervices. In uterus didelphys, individual horns are fully developed. Normally, each uterus has one fallopian tube with two cervices present. According to American Fertility Society classification of utero-vaginal anomalies, uterus didelphys belongs to class III. The cause of fusion failure is unknown. Low incidence of uterus didelphys is reflected in literature by paucity of data regarding reproductive performance. ${ }^{1}$

Most women with didelphys uterus are asymptomatic, but some may present with dyspareunia or dysmenorrhoea. It 
may also cause a variety of obstetrical complications such as spontaneous abortions, preterm labour, cervical incompetence and malpresentations. ${ }^{2}$ Rarely, renal anomalies are reported in association with didelphys uterus, since Mullerian duct develops often in association with Wolffian duct. Despite some of these complications, there are many cases of women with a didelphys uterus, that did not exhibit any reproductive or gestational challenge.

\section{CASE REPORT}

A 23 years old, unregistered primi-gravida, presented in our hospital in labour room of PGIMS, Rohtak, Haryana referred from Khanpur Medical College, Haryana, as a case of 39 weeks +4 days pregnancy with severe oligohydramnios with severe IUGR with placenta previa type IV with $\mathrm{Rh}$ negative pregnancy for safe confinement.

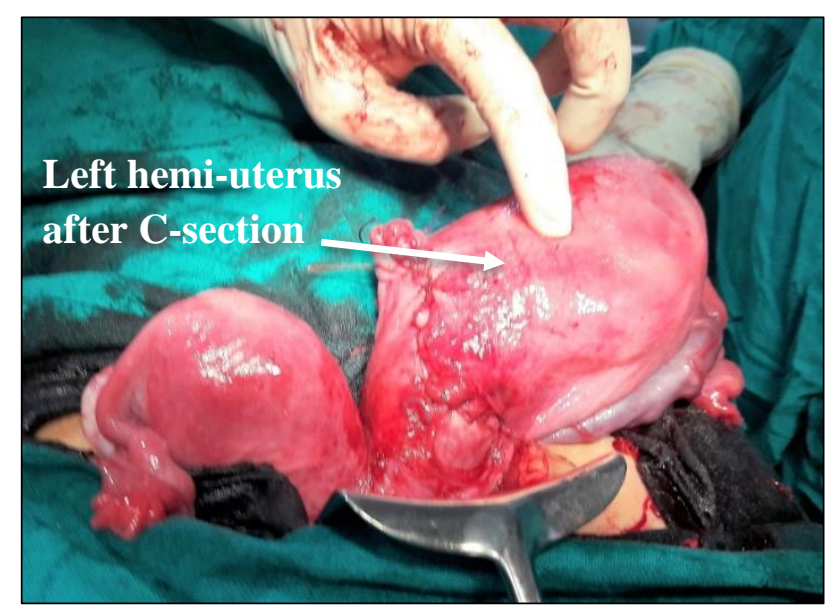

Figure 1: Anterior view of uterus didelphys with two hemi-uterus, each with its fallopian tube and ovary after caesarean section.

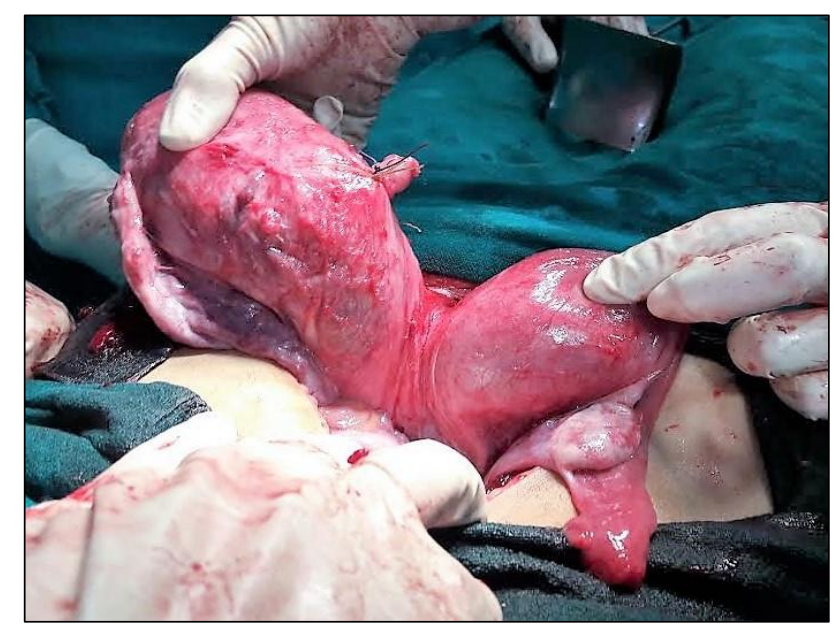

Figure 2. Posterior view of uterus didelphys showing fallopian tubes and ovaries of each hemi-uterus. The two hemi-uteri are separated by a loose fold of peritoneum.

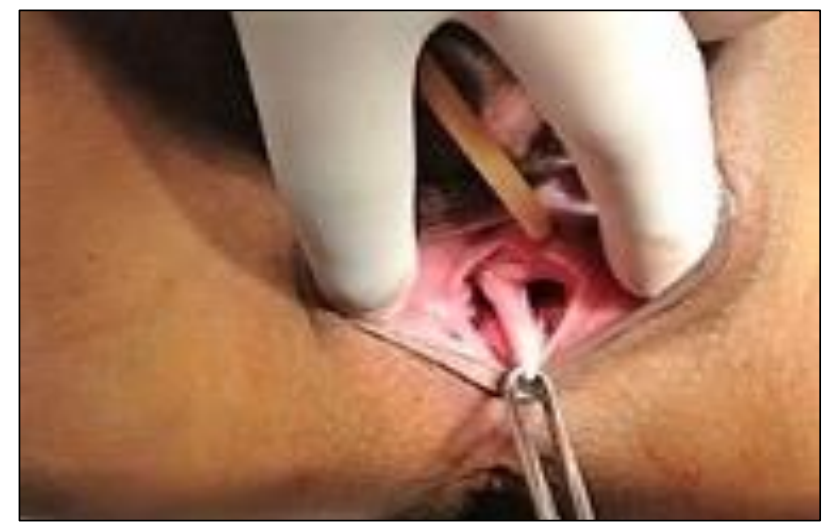

Figure 3: Longitudinal vaginal septum.

She had regular menstrual cycles and no dysmenorrhea. There was no significant past or family history. On examination, her vitals were within normal limits. Her general condition was fair, pulse rate was $78 \mathrm{bpm}$, BP was $120 / 78 \mathrm{~mm} \mathrm{Hg}$ in right arm, supine position. Her cardio-vascular and respiratory system were within normal limits. On per abdomen examination, uterus was corresponding to 32 weeks gestation with oblique lie, relaxed, with regular fetal heart rate of $142 \mathrm{bpm}$.

On local examination, there was no active bleeding. She had a USG scan report showing type IV placenta previa with severe oligohydramnios with severe IUGR. The scan had not mentioned uterus didelphys.

All her routine blood and urine investigations were normal. She was posted for caesarian section in view of type IV placenta previa with severe oligohydramnios with sever IUGR with fetal distress, under spinal anesthesia. Abdomen was opened by Pfannensteil's incision and a live, full term, female IUGR baby of $1.5 \mathrm{~kg}$ was delivered and handed over to pediatrician.

\section{Intra-operative findings}

After delivery of placenta, when the uterus was exteriorized, we observed another non- pregnant uterus of about 10 weeks size in pelvis, lying posterior and right of pregnant left hemi-uterus.

One fallopian tube and one ovary were attached to each hemi-uterus. Two cervices were felt to fingers on pervaginal examination.

Left cervix admitted one finger while right cervix admitted just the tip of finger. Two separate vaginas were seen with a longitudinal vaginal septum. The fetus was delivered from left uterus. Both ovaries and tubes appeared healthy.

An ultrasound KUB was done on day 4 and no renal anomalies were detected. She had an uneventful intraoperative and post-operative period. The mother and baby were discharged on $6^{\text {th }}$ post-operative day. 


\section{DISCUSSION}

The prevalence of Mullerian anomalies is exactly not known, but recent studies show it to be $0.1-10 \%$. Incidence of singleton pregnancy in didelphys uterus is 1:3000. Embryological cause is the complete non-fusion of two para-mesonephric ducts, results in didelphys uterus. ${ }^{3}$ Pelvic examination typically reveals double vagina and double cervix.

Helpful techniques to investigate the uterine structures are

- $\quad$ TVS and sonohysterography

- HSG

- MRI and hysteroscopy

- 3D ultrasonography has been advocated as an excellent non-invasive method to evaluate uterine malformations. ${ }^{4}$ It can accurately analyze uterine structures, contour of fundus, muscle thickness and septum length. It is best performed during secretory phase of menstrual cycle.

3D ultrasound offers $100 \%$ specificity and MRI is the most sensitive imaging modality in diagnosing uterine abnormalities.

Body of literature on didelphys uterus, although limited, generally shows that the anomaly may lead to better pregnancy outcome, as compared to other anomalies.

However, Acien's prospective observational study of reproductive outcome of females with different uterine anomalies in comparison to a normal uterus found the rate of term delivery for a didelphys uterus significantly lower than normal uterus group.

Grimbizis et al also confirmed this conclusion in a review on clinical implications of uterine malformations. ${ }^{5}$

A didelphys uterus has been shown in many case reports to occur as a part of a syndrome, more specifically known as Herlyn-Wernes-Wunderlich (HWW) syndrome, also known as Obstructed hemivagina and ipsilateral renal anomaly (OHVIRA). ${ }^{6}$ It is a very rare congenital anomaly of urogenital tract involving Mullerian and Wolffian duct. It is characterized by a triad of didelphys uterus, obstructed hemi-vagina and ipsilateral renal agenesis. ${ }^{7,8}$

In case of single pregnancy in uterus didelphys, literature shows the right hemi uterus having pregnancy predominantly. ${ }^{9}$

In uterus didelphys, non-pregnant hemi uterus is also subjected to hormonal influences as the pregnant hemi uterus and it remains as a pelvic organ posterior to the pregnant hemi uterus and hampers delivery of the fetus. ${ }^{10}$ In the present case, we are reporting a single successful pregnancy in left hemi uterus, which is very rare.

\section{CONCLUSION}

In our case report, this patient had a single successful pregnancy in left hemi-uterus, and gave birth to a girl baby by caesarean section. However, complications like IUGR and oligohydramnios were present. But the mother did not have any history of dysmenorrhoea, dyspareunia, abortion or preterm delivery. Conclusively, we can state that patients with uterus didelphys belong to high risk group and complications are increased in malformed uterus. Such cases need a meticulous prenatal care. Prompt and accurate diagnosis of uterine malformations and appropriate surgical interventions are essential to prevent complications and to provide the best possible pregnancy outcome.

\section{Clinical significance}

Uterus didelphys is a very rare Mullerian anomaly. It can present with varied gynaecological and obstetrical complications such as dysmenorrhoea, dyspareunia, recurrent pregnancy losses, IUGR, preterm labour pain etc.

\section{Funding: No funding sources \\ Conflict of interest: None declared \\ Ethical approval: Not required}

\section{REFERENCES}

1. Green LK, Harris RE. Uterine anomalies: frequency of diagnosis and associated obstetrical complications. Obstet Gynecol. 1976;47:427-9.

2. Eds-Speroff L, Friet Z. The uterus in clinical Gynaecological endocrinology and infertility. In: Eds-Speroff L, Friet Z (Eds). Clinical Gynecologic Endocrinology and Infertility, $7^{\text {th }}$ edition. Philadelphia: Lippincott Williams and Wilkins; 7th edition. 2005:132.

3. $\mathrm{Wu} \mathrm{MH}$, Huang Ke. Detection of conjenital Mullerian duct anomalies using 3D USG. J Clin ultrasound. 1997;25(9)487-92.

4. Purandare CN, Umrigar R, Bandukwalla V, Visarya $\mathrm{N}$, Purandare N. Hematometra in uterus with didelphys with obstructed right hemivagina with right renal agenesis. J Obstet Gynecol India. 2011;61(2);210-2.

5. Sohail M, Khan H, Safia S. Uterus didelphys having single pregnancy in right hemi uterus; a case report. J Chin clin medicine 2010;5;46-9.

6. Gomathy E, Sheela SR. Uterus didelphys with unilateral vaginal obstruction having single pregnancy in her right horn. J Clin Biomed Sci. 2013;3(3);143-5.

7. Li S, Qayyum A, Coakley FV, Hricak H. Association of renal agenesis and mullerian duct anomalies. J Computer Assisted Tomography. 2000;24(6):829-34.

8. Salim R, Rogan L, Woelfer B, Bacos M, Jurkovic D. Reproducibility of three-dimensional ultrasound in 
diagnosis of congenital uterine anomalies. Ultrasound Obstet Gynecol. 2003;21:578-82.

9. Grimbizis GF, Camus M, Tarlatzis BC, Bontis JN, Devroey P. Clinical implications of uterine malformations and hysteroscopic treatment results. Human Reproduction Update. 2001;7(2):161-74.
10. Acién P. Reproductive performance of women with uterine malformations. Human Reprod. 1993;8(1):122-6.

Cite this article as: Sawai D, Sharma SK, Sawai DS, Sawai U, Sharma S, Sharma A. Pregnancy in uterus didelphys delivered by caesarean section: a case report. Int J Reprod Contracept Obstet Gynecol 2017;6:5166-9. 